\title{
Lipids extracted from urines and stones of nephrolithiasis patients: clinical significance?
}

\author{
Viroj Wiwanitkit
}

Received: 3 June 2010/Accepted: 1 October 2010/Published online: 16 October 2010

(C) Springer-Verlag 2010

\section{Editor,}

I read the recent publication on lipids extracted from urines and stones of nephrolithiasis patients with a great interest [1]. Boonla et al. [1] concluded that "total lipids in centrifuged urines did not differ between nephrolithiasis and healthy subjects" and "the significant sources of lipids in patients' urine may be large lipid-containing particles, which are removed in centrifuged urines [1]." I have some concerns on this work. First, no matching case control design might imply that there might be some bias. Second, there is no exclusion of other occulted metabolic disorder in the control subjects that might lead to abnormal urination. Third, the quality control of the urine sedimentation preparation and urine analysis should be mentioned. Fogazzi et al. [2] noted that EQA programs for urine sediment were both useful and needed. Nevertheless, I would like to share some ideas on the pathological process due to urine lipid. It is no doubt that there is no difference of urine lipids between nephrolithiasis and healthy subjects; since there is no clear pathobiological process that lipid plays important roles in nephrolithiasis. Boonla et al. also mentioned for the stress due to lipids and extrapolate to the clinical significance in nephrolithiasis. This can be true when there is any proof on oxidative flux change in urine sample of nephrolithiasis case that cannot be detectable in normal subjects. For this concern, in a Boonla et al.'s earlier publication, elevation of urinary 8-hydroxydeoxyguanosine in patients with nephrolithiasis was reported demonstrating the presence of oxidative stress in patients with stone disease [3]. Finally, if it is believed that large lipid-containing particles can be removed during centrifugation then further study on non-centrifuged urine samples must be done.

\section{References}

1. Boonla C, Youngjermchan P, Pumpaisanchai S, Tungsanga K, Tosukhowong P (2010) Lithogenic activity and clinical relevance of lipids extracted from urines and stones of nephrolithiasis patients. Urol Res [Epub ahead of print]

2. Fogazzi GB, Secchiero S, Consonni D, Sciacovelli L, Zardo L, Garigali G, Verdesca S, Messa P, Plebani M (2010) An Italian External Quality Assessment (EQA) Program on Urinary Sediment. Clin Chim Acta 411(11-12):859-867

3. Boonla C, Wunsuwan R, Tungsanga K, Tosukhowong P (2007) Urinary 8-hydroxydeoxyguanosine is elevated in patients with nephrolithiasis. Urol Res 35(4):185-191
V. Wiwanitkit $(\bowtie)$

Wiwanitkit House, Bangkhae, Bangkok 10160, Thailand

e-mail:wviroj@yahoo.com 